\title{
Quantitative Estimation of Intracellular Neutral Lipids of the Yeast, Lipomyces starkeyi
}

\author{
Takafumi Naganuma, Yasuyuki UzuKa and Kentaro TanakA \\ Department of Fermentation Technology, Faculty of Engineering, \\ Yamanashi University, Takeda-4, Kofu 400, Japan
}

Received September 8, 1981

\begin{abstract}
In this paper, we present a simple and sensitive method for the assay of intracellular neutral lipids of the yeast, Lipomyces starkeyi. In this method, we used a tower-shaped mixer for cell disruption and applied a diagnostic triglycerides assay kit as a sensitive color developer. This mixer could treat 14 samples at one time. No effect of $\mathrm{pH}$ on cell disruption was detected within the $\mathrm{pH}$ range of 1.6 to 6.8 . Twenty min was chosen for cell disruption and for homogeneous dispersion of intracellular neutral lipids. The analytical results agreed well with those obtained by three conventional methods. The new method is simpler and of good reliability.
\end{abstract}

Most yeasts have the ability to accumulate neutral lipids (mainly triglycerides) and form a specific intracellular oil globule. ${ }^{1,2)}$ Little effort has been made to develop a sensitive and reliable means for the determination of the intracellular neutral lipid content. In the course of physiological studies on the triglyceride accumulation of the yeast, Lipomyces starkeyi, we were faced with the problem of determining the triglyceride content of many samples.

In our previous works, ${ }^{3,4)}$ the triglyceride content was determined by two methods. The first, total lipid extraction followed by gravimetric determination, ${ }^{3)}$ is based on the fact that a major part of the total lipid in the yeast is in the form of triglycerides. The second is determination of the volume of the intracellular oil globule by direct measurement of its diameter under a microscope. ${ }^{3,4)}$ These methods give reproducible results but are unsatisfactory due to their respective drawbacks. The gravimetric method is not very sensitive and therefore large volumes of cell culture and organic solvents are required. Direct microscopic measurement takes about $2 \mathrm{hr}$ to obtain reliable results.

Therefore, we attempted to develop a rapid, sensitive and reliable method for the determination of the intracellular triglyceride content.
The yield of intracellular triglycerides depends essentially on the degree of cell disruption. The key point of our new method was that total disruption of only a small number of yeast cells was accomplished in a test tube. Application of a diagnostic triglycerides assay $\mathrm{kit}^{5)}$ gave good results for sensitive determination.

\section{MATERIALS AND METHODS}

Organism and cultural conditions. The organism used throughout this work was Lipomyces starkeyi IAM 4753, the same strain which was employed in our previous work. ${ }^{6)}$ The yeast was grown under aerobic conditions in the simple glucose-mineral salts medium of Wickerham as described previously. ${ }^{2}$ ) Unless otherwise stated, the cells were harvested in the stationary phase of growth at an optical density of about 10.0 at $E_{660 \mathrm{~nm}}^{1 \mathrm{~cm}}$.

Disruption of the yeast cells. On the basis of experiments described in the RESULTS section of this paper, the following standard method was used for cell disruption; yeast cells in $1 \mathrm{ml}$ of culture fluid were pipetted into a test tube $(18 \times 110 \mathrm{~mm})$ containing $2.5 \mathrm{~g}$ of glass beads $(1 \mathrm{~mm} \mathrm{di}-$ ameter). The test tubes were set on a tower-shaped electric mixer (Taiyo Mix-Tower Model A-14) and shaken mechanically for $20 \mathrm{~min}$ at its highest speed $(2500 \mathrm{rpm})$. The rotary head of the mixer was connected to a vertical central pole $(170 \mathrm{~mm}$ in height) with a horizontal disc of $190 \mathrm{~mm}$ in diameter at the highest position. Fourteen test tubes could be set vertically around the disc and used 
simultaneously. Cells were disrupted completely and intracellular neutral lipids were dispersed homogeneously in the final suspension.

Assay of neutral lipids. Twenty $\mu \mathrm{l}$ of the disrupted cell suspension was immediately pipetted into another test tube and $3.0 \mathrm{ml}$ of the test solution of a Cleantech TG assay kit (kindly supplied by Iatron Laboratories Inc., Higashikanda, Chiyoda-ku, Tokyo) was added. The reaction mixture contained $0.1 \mathrm{M}$ Tris- $\mathrm{HCl}$ buffer $(\mathrm{pH} 7.0)$, ATP, enzymes (lipoprotein lipase, glycerokinase, L- $\alpha-$ glycerophosphate oxidase and peroxidase), 4-aminoantipyrine and $N, N$-diethyl- $m$-toluidine. In the reaction mixture, a sequence of reactions by lipoprotein lipase, glycerokinase and L- $\alpha$-glycerophosphate oxidase quantitatively converted neutral lipids into dihydroxyacetone phosphate and hydrogen peroxide via glycerol and $\mathrm{L}-\alpha-$ glycerophosphate. The peroxidase catalyzes the reaction between hydrogen peroxide, 4-aminoantipyrine and $N, N$ diethyl- $m$-toluidine to form a quinoid pigment. After 20 min incubation at $37^{\circ} \mathrm{C}$, the test tubes were centrifuged at $2500 \times g$ for $10 \mathrm{~min}$ and the red colored supernatant fraction was measured colorimetrically at $E_{545 \mathrm{~nm}}^{1 \mathrm{~cm}}$.

Total lipid extraction and analysis. The methods used for the total lipid extraction followed by gravimetric determination were those described by Naganuma et al. ${ }^{3)}$ and Watson and Rose. ${ }^{7)}$ The extracted lipid was chromatographed on silica gel sintered Chromarod-S (Iatron Laboratories, Inc.) using benzene-methanol $(98: 2$, by vol.) as the solvent system. Lipid classes were separated and the amounts were determined by thin-layer chromatography ${ }^{8,9)}$ (Iatroscan Model TH-10).

Chemicals. All chemicals were of reagent grade or the highest purity available commercially.

\section{RESULTS}

Effect of shaking time on cell disruption and on the amount of neutral lipid liberated from the cells

Figure 1 shows the effect of shaking time on the degree of cell disruption and on the amount of neutral lipid liberated from the cells. The amount of neutral lipid increased parallel with increased cell disruption. Complete cell disruption was achieved within $20 \mathrm{~min}$.

Effect of washing and freeze storage of yeast cells on the neutral lipid assay

As ordinary extraction methods for lipid determination required complicated oper-

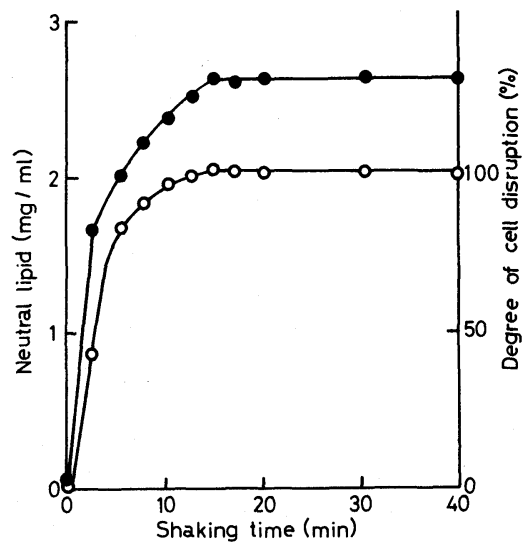

FIG. 1. Effect of Shaking Time on Cell Disruption and the Amount of Neutral Lipid Liberated from L. starkeyi.

The yeast was grown in the glucose-mineral salts medium of Wickerham, and the cells were harvested in the stationary phase of growth. On eml of fluid of each culture plus cells was pipetted into a test tube $(18 \times 110 \mathrm{~mm})$ containing $2.5 \mathrm{~g}$ of glass beads ( $1 \mathrm{~mm}$ diameter). The test tubes were set on a tower-shaped electric mixer (Taiyo Mix-Tower Model A-14) and shaken for the indicated period. The amount of neutral lipids was determined by the enzymatic method. The degree of cell disruption was followed by counting apparently intact cells under a microscope. amount of neutral lipid; $\bigcirc$, degree of cell disruption.

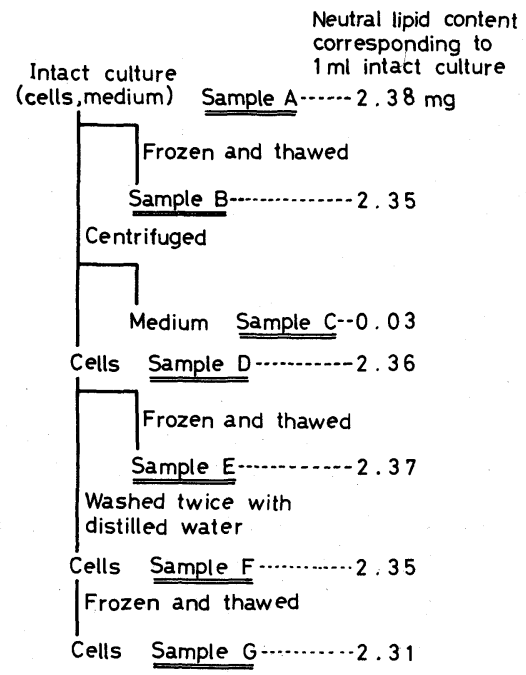

FIG. 2. Effect of Centrifugation, Washing and Freezing on the Cellular Neutral Lipid Content.

Harvesting and washing of the cells was performed by centrifugation at $2500 \times \mathrm{g}$ for $5 \mathrm{~min}$. Cells were stored at $-20^{\circ} \mathrm{C}$ for $24 \mathrm{hr}$. Cells corresponding to $1 \mathrm{ml}$ of intact culture fluid were disrupted by shaking for $20 \mathrm{~min}$ at room temperature. Other conditions were the same as described in Fig. 1. 
ations, ${ }^{3,7,10)}$ only a small number of assay samples were subjected to estimation at one time. In order to assay many samples with the new method at one time, the effects of centrifugation, washing and freeze storage of the yeast cells on the neutral lipid contents were tested. Aliquots of culture fluid were frozen, centrifuged and/or washed as described in Fig. 2, and samples corresponding to $1 \mathrm{ml}$ of intact culture fluid plus yeast cells were analyzed for neutral lipid contents. Each value in Fig. 2 represents the average of three determinations. The medium fraction of intact culture contained a negligible amount of neutral lipids. Centrifugation, washing and freeze storage did not affect the results. The results also revealed that separation and washing of the cells from the culture fluid were unnecessary for determining the cellular neutral lipid content of $L$. starkeyi.

\section{Effect of $p H$ on the amount of neutral lipid} liberation from the cells

In order to use the culture fluid plus cells in the estimation of cellular neutral lipid content, it was necessary to examine the effect of $\mathrm{pH}$ on neutral lipid liberation because throughout growth the $\mathrm{pH}$ of the culture fell from 5.4 to 1.8 (Fig. 6). Cells were washed twice with McIlvain buffer or $0.2 \mathrm{M}$ acetate buffer and resuspended in the same buffer solution and disrupted. Figure 3 shows that the change in $\mathrm{pH}$ did not affect the analytical results.

\section{Neutral lipid liberation as a function of cell concentration}

Cell suspensions ranging from $4.2 \times 10^{7}$ to $3.0 \times 10^{8}$ cells per $\mathrm{ml}$ were used for the analysis. These concentrations correspond to those at the retardation and stationary phases of growth when L. starkeyi is cultured in a medium containing 3\% glucose (Fig. 6). The results of these experiments are shown in Fig. 4 where the amount of neutral lipid is plotted against cell concentration. A straight line was drawn through the points. For samples taken from the retardation and stationary phases of growth which were submitted for analysis, $1 \mathrm{ml}$

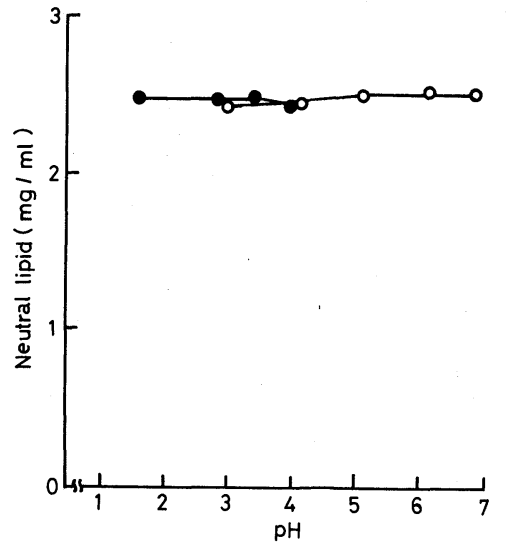

FIG. 3. pH Dependence of the Neutral Lipid Liberation from Cells of L. starkeyi.

Cells were disrupted in $0.2 \mathrm{M}$ acetate buffer (O) and in McIlvain buffer ( $O$ ).

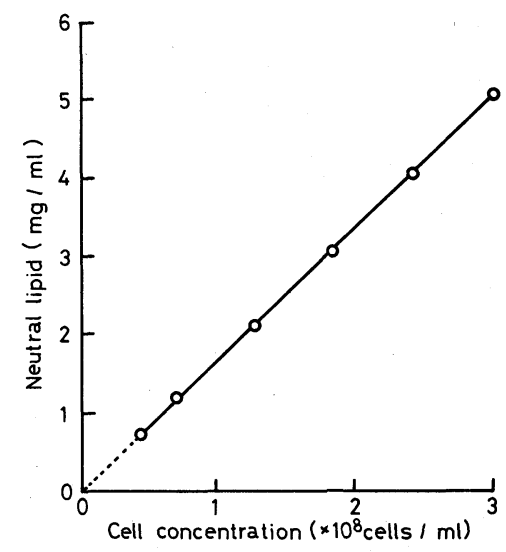

FIG. 4. Relationship between the Amount of Neutral Lipid Liberated and Cell Concentration of L. starkeyi.

Experimental conditions were the same as described in Figs. 1 and 2.

of culture fluid plus cells was enough to determine the neutral lipid content.

\section{Reliability of the new method.}

In order to evaluate the new method, we compared the method with other methods which were used in our previous work ${ }^{3)}$ and in the work of Watson and Rose. ${ }^{7}$ L. starkeyi was grown in the synthetic medium of Wickerham, and samples were withdrawn periodically. About 0.5 liters of culture was used for our previous extraction method whilst 2 liters was used for the method of Watson and 


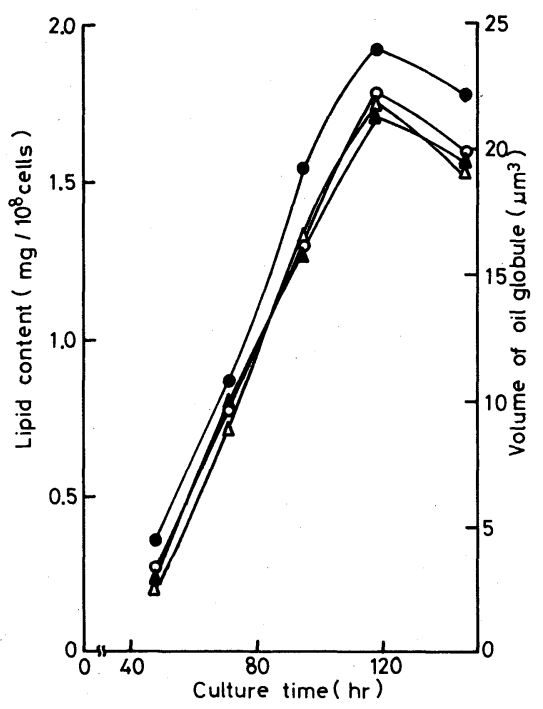

Fig. 5. Comparison of the New Assay Method with Other Methods.

O, total lipid extraction followed by gravimetric determination; $O$, total lipid extraction followed by thinlayer chromatographic analysis of the neutral lipid fraction; $\boldsymbol{\Delta}$, volume of intracellular oil globule calculated by direct measurement of the diameter under a microscope; $\triangle$, new method.

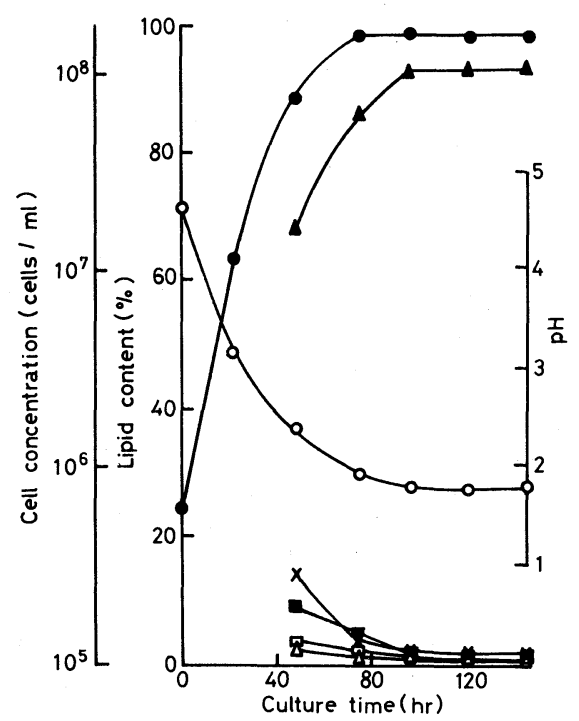

Fig. 6. Variation Profiles of Total Lipid Composition $\mathrm{pH}$ of the Medium and Cell Concentration throughout the Culture.

- cell concentration; $\mathrm{O}, \mathrm{pH}$ of the medium; $\boldsymbol{\Delta}$, triglyceride; $\triangle$, diglyceride; $\square$, free fatty acid; $\square$, ergosterol; $\times$, phospholipid.
Rose. But, for the new method and for the volume calculation method, $5 \mathrm{ml}$ and $10 \mathrm{ml}$ of culture fluid plus cells, respectively, were required to attain similar analytical results. We also observed changes in cellular total lipid composition using thin-layer chromatography $^{8,9)}$ with an Iatroscan as a detector. As shown in Fig. 5, data obtained by the three diverse methods, the new method, thin-layer chromatographic analysis of triglycerides in the total extractable lipid and the intracellular oil globule volume calculated from direct measurement of the diameter, agreed well with each other. A variation profile of total lipid content obtained by the extraction method was similar to that of the triglyceride content. This fact indicates that the major component of cellular total lipid is triglyceride. Figure 6 also shows that the detectable minor components were phospholipids, free fatty acids, ergosterol, and diglycerides. Their contents decreased as the culture time progressed.

\section{DISCUSSION}

Yeasts have been recognized as potent triglyceride producing organisms. ${ }^{11 \sim 14)}$ During World Wars I and II, this property was investigated in Germany as a possible means of edible oil production. This productivity has been calculated by conventional methods based on solvent extraction followed by gravimetric analysis. ${ }^{3,10)}$ Very little effort has been made to improve the analytical method used in small scale experiments.

To develop a simple and sensitive analytical method for measuring intracellular triglyceride content, we adopted a method of mechanical shaking of yeast cells with glass beads, because mechanical shaking can disrupt the yeast cell wall and homogeneously disperse olive oil even in an aqueous buffer solution. Firstly, we tried to apply the B. Braun homogenizer ${ }^{7,10}$ ) for this purpose, but it failed to handle many samples at one time. Introduction of a towershaped mechanical mixer solved the problem. The mixer could hold 14 test tubes and shake them all at one time. The size of the glass beads 
added to the test tubes was important for the disruption of yeast cells. Bigger beads did not move vigorously in the test tube and smaller beads did not crush the yeast cells. One of the problems predicted for the use of glass beads was the increase in $\mathrm{pH}$ due to solubilization of alkaline metal(s) from glass beads. Fortunately, the change in $\mathrm{pH}$ between 1.6 and 6.8 did not affect the analytical results (Fig. 3). Another problem of mechanical disruption was whether homogeneous dispersion of intracellular neutral lipids could be achieved or not. In a preliminary experiment, we took 20 aliquots from a cell homogenate and made color developments. Absrobance at $545 \mathrm{~nm}$ for these samples was consistent within technical error of $2 \%$. Addition of various detergents, for example, sodium laurylsulfate, sodium deoxycholate and polyvinylalcohol, at the disruption stage did not improve the experimental results. These facts suggest that intracellular neutral lipids must be dispersed homogeneously at the end of cell disruption.

The principle of the one-step color reaction with the Cleantech TG assay kit is based on the specific enzymatic estimation of glycerol which is liberated from neutral lipids by the action of lipoprotein lipase. ${ }^{5)}$ Quantitative analysis of the total extractable lipid from $L$. starkeyi revealed that the amount of diglycerides plus monoglycerides is about $0.5 \%$ of total lipid throughout the culture (Fig. 6). Therefore, the new method can be substantially used for the estimation of cellulartriglyceride content of the yeast without having to consider other neutral glycerides in the cells.
Dilution of one part of the test reagent to 3 parts of distilled water afforded economical use of the test reagent without a decrease in sensitivity.

An analogous diagnostic triglycerides assay kit (Anasolve TG, Daiichi Pure Chemicals Co. Ltd., Tokyo) was also useful for the same purpose.

Acknowledgment. The authors are grateful to Iatron Laboratories Inc., Tokyo, for generously supplying of the Cleantech TG kit and for making their facilities and Iatroscan available for us.

\section{REFERENCES}

1) Y. Uzuka, T. Kanamori, T. Koga, K. Tanaka and T. Naganuma, J. Gen. Appl. Microbiol., 21, 157 (1975).

2) H. Korenaga, T. Naganuma, Y. Uzuka and $\mathbf{K}$. Tanaka, Nippon Nôgeikagaku Kaishi, 51, 449 (1977).

3) T. Naganuma, Y. Uzuka, K. Tanaka and T. Koga, Nippon Nôgeikagaku Kaishi, 49, 335 (1975).

4) M. Sodeyama, Y. Uzuka and K. Tanaka, Nippon Nôgeikagaku Kaishi, 46, 503 (1972).

5) T. Nishina, Bunseki, 3, 170 (1978).

6) Y. Uzuka, T. Naganuma, K. Tanaka and Y. Odagiri, J. Gen. Appl. Microbiol., 20, 197 (1974).

7) K. Watson and A. H. Rose, J. Gen. Microbiol., 117, 225 (1980).

8) H. Kaneko, Yukagaku, 22, 449 (1973).

9) T. Itoh, H. Waki and H. Kaneko, Agric. Biol. Chem., 39, 2365 (1975).

10) T. Itoh and H. Kaneko, Yukagaku, 23, 350 (1974).

11) M. Hongô, "Biseibutsukôgyô," ed. by T. Asai, Asakura Shoten Inc., Tokyo, 1956, pp. $451 \sim 477$.

12) H. Iwamoto, "Shishitsukagaku," Vol. II, ed. by S. Funabashi et al., Kyôritsushuppan Inc., Tokyo, 1958, pp. $143 \sim 157$.

13) D. Watanabe, Kagaku to Seibutsu, 5, 732 (1967).

14) Y. Uzuka, "Kôbo no Riyô to Kaihatsu," ed. by Y. Akiyama, Japan Scientific Societies Press, Tokyo, 1979, pp. $171 \sim 183$. 